\title{
British Asian Muslim Women, Multiple Spatialities, and Cosmopolitanism
}

\author{
Fazila Bhimji \\ New York: Palgrave Macmillan, 2012. 176 pages.
}

This book is a valuable contribution to the growing body of research on the experiences and identities of British Muslim women. Intersections between gender, ethnicity, and Islam only became a prominent theme in British social sciences when the need for a careful and fair investigation of Muslim women's realities arose during the last decade due to the unfolding of several Islamoriented policy debates (i.e., politicians' critiques of the niqab) and the introduction of legislation designed to tackle "violent extremism" and "honor crimes." The way these matters were represented in the media and policy documents has recycled and reinforced the age-old Orientalist stereotypes of Muslim women as silent and passive victims of patriarchal oppression.

The author challenges these stereotypes, which are often expressed through depictions of Muslim women as spatially anchored and restricted. Thus this book focuses on cosmopolitan practices, particularly spatial and social transitions, among second-generation British Asian Muslim women. This approach brings together Bhimji's earlier work, in particular articles dealing with these women's online interactions focused on religion (2005), travelling to and belonging in South Asia (2008), and religious study circles (2009). The monograph is updated with new themes (e.g., case studies of prominent artists) and applies the analytic lens (viz., the concepts of spatialities and cosmopolitanism) adopted in her article on traveling overseas, to all of the issues discussed.

The idea of these women crossing geographical, political, and social boundaries runs throughout the book in order to identify how the stereotype may be challenged. Bhimji demonstrates that cosmopolitanism, commonly understood as a rejection of localized identities in favor of global ones and which is based on social, cultural, and economic privilege, may also be interpreted as a willingness to cross boundaries and engage with difference. As boundaries and differences form a range of spaces, Bhimji builds her argument by utilizing a multi-method approach to her data. Not only does she engage in "traditional" ethnographic research with the women attending mosquebased study groups in northern England, as well as women who travel to South Asia and beyond, but she also includes media texts, online discussion transcripts, and case studies (i.e., a comedian, a poet, a visual artist, and a political 
activist). This multi-faceted strategy works well, as it recognizes the complex nature of socially constructed boundaries.

The introduction sets the scene by reviewing the background to the research and examining the theoretical perspective. The discussion on research that attempts to destabilize essentialist constructions of Muslim women is purposefully selective, presenting the main argument and not overloading the reader with details. It is followed by an explanation of why cosmopolitanism is more useful than multiculturalism for explaining the themes emerging from the data: The latter offers a notion of collectivity "among a group of people with a common culture," whereas the former "recognizes the fact that individuals who may belong to a particular cultural community may exhibit and display varying and fragmented identities" (p. 12). The introduction also includes an overview of methodological issues that characterize the research, especially participant recruitment in the context of the author's positionality. Bhimji's own professional career seems to reflect spatial transitions similar to those of the participants: As she acknowledges in the book, she is of South Asian origin, lived for a long time and completed her doctorate in California (p. 22), and obtained her first permanent academic position in northern England. Thus she is interestingly positioned to examine the participants' identity struggles. However, she is careful to trace both similarities and differences that might characterize and shape the power dynamics (p. 20), an undertaking that provides good insight into the insider/outsider dilemmas she experienced while conducting her research.

Chapters 2-6 consider different thematic strands of the research. In chapter 2, Bhimji focuses on how the British media's binary representation of British Asian Muslim women: the "subjugated victim" vs. the "fanatical terrorist." She draws this conclusion from her analysis of the media's coverage regularly raised "moral panics" in the United Kingdom: forced marriages and the niqab (also known as the burka, although they are different garments). These issues are commonly presented as evidence of the incompatibility of British Asian Muslim culture with "British culture." The author protests this simplistic statement by highlighting the diversity of British Muslims who should not be treated as a homogenous entity, but rather as a group comprised a variety of ethnic, linguistic, class, educational, and political backgrounds.

Chapter 3 is based on the analysis of data generated through interviews with a range of women who travel to their parents' homelands. Bhimji finds that the relationship between these young women and these parental homelands, as well as the United Kingdom, is both complex and variegated, for their religious and social identities emerge in global and cosmopolitan, rather 
than national, contexts. Chapter 4, which looks at women's mobilization in mosque-based study centers, is important because it focuses on women's spaces emerging in still largely male-dominated institutions. She also documents how women's various positionalities are enacted in mosques through interaction with women and men.

Chapter 5 includes three case studies of British Asian Muslim women working in the arts. It looks at how they simultaneously draw from both global and local contexts to form networks and connections, as well as how they cross gender, ethnic, and religious boundaries in the course of their artistic and political work. For instance, she describes how a showcased comedian successfully negotiated her way into comedy clubs that, in England, are mostly the domain of white middle-class young male audiences (p. 101). Chapter 6, which examines data obtained from online discussion groups populated by Muslim men and women, analyzes gendered interactions and formulations and contestations of religious identity. It contradicts the stereotype of the subjugated Muslim woman by offering examples of their refusal to be criticized by male discussants on religious grounds.

Unfortunately, there are some weak points, too. First, these include factual inaccuracies. For example, Bhimji states that the French government banned the hijab in public spaces (p. 3), whereas in fact this ban, introduced in 2004, only applied to state institutions, in particular schools. In 2011, a blanket ban was applied to wearing the niqab. Second, there are some missing in-text references, as in the discussion of Dwyer's work on veil and identities (p. 8). Third, there are some logical discontinuities in presenting the western context for these debates. For instance, at one point she states that feminist scholars see women who visibly express their religious identity as necessarily conforming to patriarchal norms (p. 4), but some pages later acknowledges that feminist scholarship does not view Muslim women as a homogenous group (p. 8). In fact, the task of contesting the media-fuelled stereotype of "the Muslim woman" has been taken up by many third-wave feminist scholars, both Muslim and non-Muslim (e.g., Haleh Afshar, Leila Ahmed, Miriam Cooke, and Myra Macdonald).

The final concern relates to the treatment of interview and online data. Interviewees are granted anonymity (just personal; the mosque names are retained), but there is no discussion of the ethical decisions made while collecting the data from the website. We do not know the author's position on the need to obtain these contributors' informed consent, and the information regarding changing/removing their online names is not given. This is a common omission among authors who are just beginning to utilize online methods. But 
as that section of the research was conducted prior to 2005, there was perhaps sufficient time to remedy this problem and provide this important ethical discussion before publication.

These concerns notwithstanding, the reviewed monograph is definitely a useful book that provides a wealth of detail and interesting analysis of data illustrating British Asian Muslim women's agendas as transcending gender, religious, and ethnic identities. The multi-method approach provides a depth of data that allows for a clear narrative and poignant observations. The decision to use cosmopolitanism, rather than the much-discussed multiculturalism, as an analytical notion has helped yield new insights and questions for further research.

Anna Piela

Research Assistant, School of Education University of Leicester, Leicester, United Kingdom 